\title{
Depoimentos - Cadernos Nietzsche
}

Cadernos Nietzsche es una revista universitaria de investigación y difusión del pensamiento y la obra de Nietzsche. Está dirigida a investigadores, profesores, estudiantes y estudiosos de este autor. Publica artículos originales de investigación y está abierta a aportaciones de estudiosos de orientaciones diversas y provenientes de las áreas geográficas más variadas. Ocasionalmente publica números en los que se informa sobre la investigación nietzscheana en otros países, facilitando así un continuo diálogo e intercambio entre los especialistas a nivel internacional.

La secuencia de la publicación es semestral, combinando números monográficos y números misceláneos, que brindan al lector un panorama representativo del rumbo de la investigación nietzscheana en Europa y en América. Cadernos Nietzsche dedica, igualmente, amplia atención al examen y crítica de las novedades bibliográficas, la edición de la obra del filósofo en los distintos idiomas y la publicación de elencos bibliográficos especializados. Cadernos Nietzsche abre, pues, un espacio para la publicación de trabajos de investigación en el ámbito de los estudios relativos a la obra y el pensamiento de Nietzsche.

Es, pues, una revista que se dirige especialmente a investigadores interesados en este autor, pero también a todo el que se interesa por el pensamiento filosófico en sentido amplio. Pues mientras el especialista puede encontrar nuevos enfoques de un determinado problema en su ámbito de trabajo, el lector aficionado se encontrará allí artículos, traducciones, revisiones críticas 
y reseñas de libros que pueden alimentar su curiosidad y ampliar su formación. Cadernos Nietzsche combina así el rigor académico con la originalidad de las investigaciones, sin olvidar la apertura y pluralidad necesarias en una publicación filosófica que quiere interesar también al lector culto en general. En cualquier caso, por su contrastada calidad está indexada en diversas bases de datos de revistas científicas.

Por su larga trayectoria, por la gran cantidad de estudios y materiales que lleva a cumulados y por el alto nivel de competencia que ha alcanzado, Cadernos Niezsche constituye una aportación científica de la que sus promotores, así como la Universidad de Sao Paulo que la alberga pueden sentirse orgullosos al situar una línea de trabajo filosófico desarrollada en Brasil en el más alto nivel de calidad de los estudios internacionales.

Diego Sánchez Meca

Director del Dpto. de Filosofía, Uned, Madrid Presidente de la Sociedad Española de Estudios sobre Nietzsche, SEDEN

Cadernos Nietzsche es una revista importante sobre la investigación de la filosofía de Nietzsche, en la medida en que recoge la actividad de los investigadores brasileños, fundamentalmente, dando conocer a la comunidad filosófica sus investigaciones. Destaca por su edición cuidada, por su periodicidad y acceso on line, su apertura hacia los investigadores más jóvenes y su orientación de publicar las investigaciones que se llevan a cabo en otros países, lo cual la enriquece y la internacionaliza. Uno de sus grandes objetivos ha sido el traducir artículos de especialistas en la obra de 
Nietzsche de primera fila, europeos y americanos, para ponerlos al servicio de la investigación internacional. Al mismo tiempo que ha tenido un especial interés en reunir en una sire de números el estado de la investigación sobre Nietzsche en los distintos países, estableciendo un verdadero foro de discusión filosófica.

Luis Enrique de Santiago Guervós Professor da Universidade de Málaga Membro do SEDEN 